\title{
Clinical and prognostic correlates of EEG in open-heart surgery patients
}

\author{
K A SOTANIEMI \\ From the Department of Neurology, University of Oulu, Oulu, Finland
}

SUMMARY Sixty-five patients undergoing cardiac valve replacement were followed for one year by electroencephalography (EEG). Occurrence of delta or sharp wave disturbances or low frequency of dominant activity before operation was found to have prognostic significance. The degree of EEG change after operation correlated with clinical signs of cerebral involvement, and predicted the later course.

The risk of cerebral disorders arising during open-heart surgery has been established in a number of clinical and experimental studies. ${ }^{1-4}$ Extracorporeal circulation may expose the central nervous system (CNS) to disturbances in blood flow, ${ }^{5}$ and metabolic changes probably due to decreased oxygen availability have been reported. ${ }^{56}$ However, the causes of cerebral complications still are controversial and a single determinant can rarely be identified. ${ }^{7-9}$ Despite technical improvements, cerebral disorders continue to occur ${ }^{10-12}$ suggesting a need to obtain more objective and detailed information of the methods used for examination of the CNS. It is evident that clinical investigation usually reveals only the most severe complications; therefore more accurate indicators of brain damage are required.

The electroencephalogram (EEG) is useful for monitoring cerebral circulation during operation. ${ }^{13} 14$ Development of the cerebral function monitor (CFM), ${ }^{16} 16$ has made it possible to detect untoward events, but the CFM has not gained unreserved acceptance because it is costly and offers only a rough estimate of the quantitative EEG. Although more sensitive methods for EEG-monitoring during surgery have been proposed, ${ }^{17}$ conventional EEG recorded before and after operation remains the most practical tool for evaluation of the CNS effects of surgery.

The present study was undertaken to assess the clinical correlates and the prognostic value of the conventional EEG in open-heart surgery.

Address for reprint requests: Kyösti Sotaniemi, MD, Department of Neurology, University of Oulu, 90220 Oulu 22, Finland.

Accepted 14 April 1980

\section{Patients and methods}

Patients and operative procedures Sixty-five consecutive patients undergoing cardiac valve replacement surgery were investigated. There were 22 women and 43 men aged from 15 to 65 years, the mean age being $43.0 \pm 10.4$ years.

Aortic valve replacement was done in 44 cases, mitral in 16 cases and both of the valves were repaired in five cases. The prostheses were of the Björk-Shiley type. All the patients were operated upon with moderate hypothermia (oesophageal temperature $30-32^{\circ} \mathrm{C}$ ). A Rygg-Kyvsgard bubble oxygenator was used and extracorporeal circulation was carried out with moderate haemodilution and non-pulsatile flow. The patients were divided into two groups according to the clinical findings at the first follow up: Group NC (no cerebral complications, $\mathrm{N}=33$ ) and Group $\mathrm{CC}$ (cerebral complications present, $\mathrm{N}=28$ ). The groups were similar for age, sex and the main cardiological diagnoses.

Design of the study The protocol of the study is presented in fig 1. Every patient underwent two preoperative (coded PRE-OP) neurological and EEG investigations on the fifth and second day before operation. The investigations were repeated five times (10 days, two months, five months, eight months and one year after operation) during the follow-up period of one year. The examinations after operation are coded using the ordinal of the investigation (from I to $\mathrm{V}$ ) together with the abbreviation FU (follow-up): For example the first postoperative EEG is coded I FU EEG.

Neurological evaluation A full neurological investigation was performed immediately before or after the EEG recordings. Signs present before operation were not listed as new findings after operation.

EEG The EEGs were recorded using a 16-channel machine (Mingograph EEG 16, Elema-Schönander) under standard conditions (time constant $0.3 \mathrm{~s}$, 


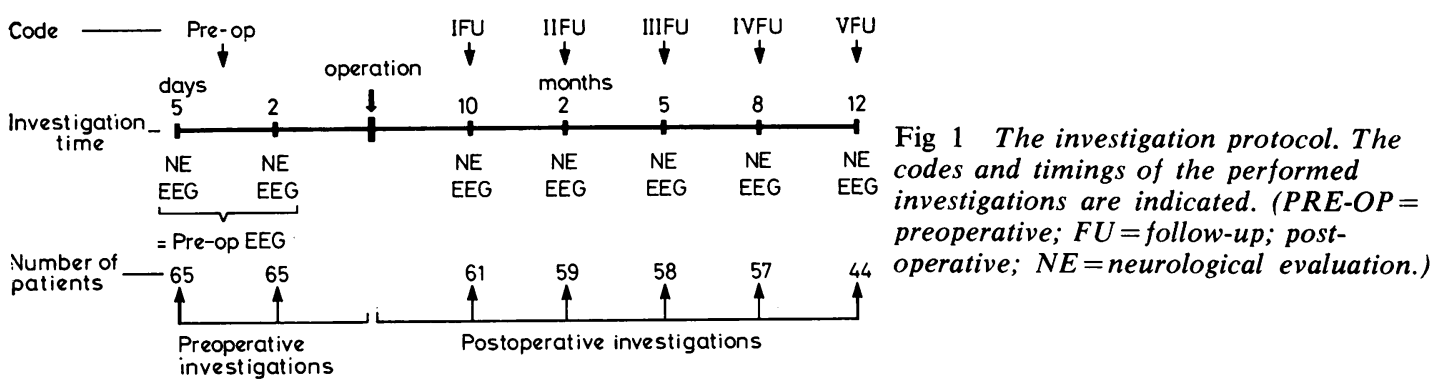

high pass filter from $70 \mathrm{c} / \mathrm{s}$, amplification $100 \mu \mathrm{V}$ $=1 \mathrm{~cm}$ or $50 \mu \mathrm{V}=1 \mathrm{~cm}$, paper speed $3 \mathrm{~cm} / \mathrm{s}$ : patient awake, semi-reclining position). Silver electrodes were placed on the scalp according to the international 1020 system. ${ }^{18}$ Four standard settings were used. The recording time was at least $30 \mathrm{~min}$ in all the investigations. Hyperventilation and photic stimulation were used as activation procedures in all but the first follow-up examination.

The EEG interpretation was carried out using conventional methods of evaluation. ${ }^{19-21}$ The classification of normality was done using the following gradation: (1) normal; (2) slightly abnormal: dominant activity within normal ranges (or slowing not more than $1 \mathrm{c} / \mathrm{s}$ when compared with a previous recording of the same individual during the followup period), short episodes of theta or delta activity seen in some few occasions: (3) moderately abnormal: slow dominant activity $(<8 \mathrm{c} / \mathrm{s})$ or slowing with $\geqslant 1 \mathrm{c} / \mathrm{s}$ in the same individual; presence of intermittent delta episodes: (4) severely abnormal: no alpha activity, abundant or continuous delta activity.

The mean value of the two recordings before operation was considered as the basic preoperative state (PRE-OP EEG) with which the EEGs after operation were compared. The two recordings before operation were found to differ from each other in only four cases: in these cases classification was done according to the more abnormal of the recordings. The frequency of the dominant activity was counted manually, and the mean value of at least four representative activity periods was used.

Student's $t$ test was used in the statistical analyses (the test for paired samples in calculating the difference between preoperative and postoperative results; the test for independent means in comparing the patient groups with each other).

\section{Results}

Clinical aspects Neurological signs of CNS disorders after operation were detected in 31 patients. Three patients died within eight days of operation. Brain damage was the cause of death in two patients and one further patient died of other causes. Symptoms of a hemiparesis were found in 19 cases, and the remaining patients exhibit either aphasia, confusion, brain stem or cerebellar signs. These symptoms were slight and usually reversible. Residual signs were still present in five cases one year after operation. (The clinical findings in a larger sample from which the present patients form a part have been reported earlier. ${ }^{12}$ )

CLINICAL CORRELATES OF EEG

General EEG evaluation Follow-up of the incidences of abnormal EEG in the NC and CC groups is presented in fig 2 . The groups were similar before operation, the incidences of abnormal EEG being $47 \%$ (NC) and $52 \%$ (CC). By contrast, considerable differences were seen after operation: an abnormal EEG was seen in $67 \%$ (22 cases out of 33) in the NC group and in $97 \%$ ( 27 cases out of 28 ) in the CC group at first follow up.

The EEG changes improved in both groups but the CC cases took longer to recover than the NC patients: the EEG restored to its PRE-OP state over two months in the NC group, but it took up to five months in the other group. One year after surgery the incidence of an abnormal EEG

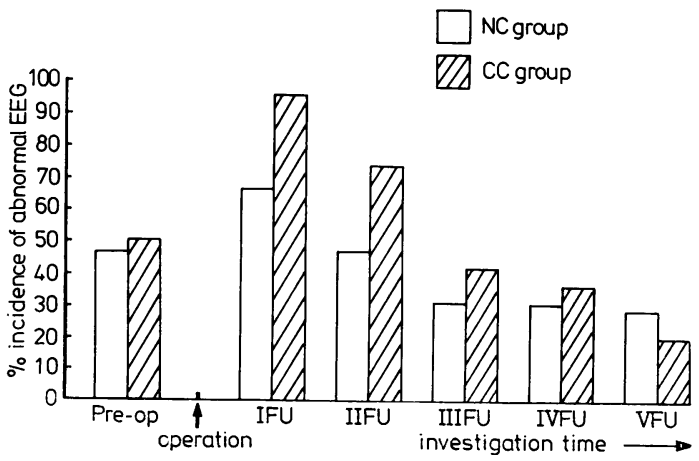

Fig 2 Follow-up of the incidence of abnormal EEG in the postoperatively non-complicated (NC) and cerebrally complicated (CC) patient groups. 
decreased to $29 \%$ in the NC group and to $20 \%$ in the CC group.

EEG impairment after operation was evident in $39 \%$ of the NC cases and in $75 \%$ of the CC patients. Deterioration of a previously normal EEG after operation occurred in $44 \%$ and $92 \%$ in groups NC and CC respectively, and an increase of previous abnormalities approved in $33 \%$ and $60 \%$ respectively.

Nature of EEG abnormalities The principal types of EEG abnormalities are shown in table 1. The greatest difference between the groups after operation was seen in delta range abnormality which increased almost sixfold and disappeared more slowly in the complicated group when compared with the non-complicated cases. Generally, the activity patterns were similar in both groups while the frequency changes formed the main differences.

Delta range activity of diffuse and continuous type was the main abnormality in 18 cases at the first follow-up investigation: $14(78 \%)$ of the cases displayed neurological signs of hemisphere damage. Thus delta activity was seen in $12 \%$ of the NC cases and in $50 \%$ of the CC cases. The clinical groups showed no significant differences in the appearance of other forms of abnormalities (table 1). Two months after surgery (II FU) delta range disturbances were not

Table 1 Main abnormal activity in the postoperatively non-complicated $(N C)$ and complicated $(C C)$ patient group

\begin{tabular}{|c|c|c|c|c|c|c|c|c|}
\hline \multirow[t]{3}{*}{$\begin{array}{l}\text { Investigation } \\
\text { time (code) }\end{array}$} & \multicolumn{2}{|c|}{$\begin{array}{l}\text { Number of } \\
\text { patients }\end{array}$} & \multicolumn{6}{|c|}{$\begin{array}{l}\text { Percentage number of cases with } \\
\text { various types of abnormal EEG activity }\end{array}$} \\
\hline & \multirow[t]{2}{*}{$n c$} & \multirow[t]{2}{*}{$c c$} & \multicolumn{2}{|c|}{ Delta } & \multicolumn{2}{|c|}{ Theta } & \multicolumn{2}{|c|}{$\begin{array}{l}\text { Sharp } \\
\text { waves }\end{array}$} \\
\hline & & & $\overline{N C}$ & $C C$ & $N C$ & $\overline{C C}$ & $\overline{N C}$ & $\overline{C C}$ \\
\hline $\begin{array}{l}\text { PRE-OP } \\
\text { I FU } \\
\text { II FU } \\
\text { III FU } \\
\text { IV FU } \\
\text { V FU }\end{array}$ & $\begin{array}{l}34 \\
33 \\
32 \\
32 \\
32 \\
24\end{array}$ & $\begin{array}{l}31 \\
28 \\
27 \\
26 \\
25 \\
20\end{array}$ & $\begin{array}{c}5 \cdot 9 \\
15 \cdot 2 \\
0 \\
0 \\
0 \\
0\end{array}$ & $\begin{array}{c}6 \cdot 5 \\
39 \cdot 3 \\
14 \cdot 8 \\
7 \cdot 7 \\
0 \\
0\end{array}$ & $\begin{array}{l}38 \cdot 2 \\
48 \cdot 5 \\
43 \cdot 8 \\
28 \cdot 1 \\
31 \cdot 3 \\
29 \cdot 2\end{array}$ & $\begin{array}{l}35 \cdot 5 \\
53 \cdot 6 \\
51 \cdot 9 \\
30 \cdot 8 \\
36 \cdot 0 \\
20 \cdot 0\end{array}$ & $\begin{array}{l}2 \cdot 9 \\
3 \cdot 0 \\
3 \cdot 1 \\
3 \cdot 1 \\
3 \cdot 1 \\
0\end{array}$ & $\begin{array}{l}9 \cdot 7 \\
3 \cdot 6 \\
7 \cdot 4 \\
3 \cdot 8 \\
0 \\
0\end{array}$ \\
\hline
\end{tabular}

seen in the NC group, but it took five months (III FU) for them to disappear in the other group.

The course of appearance of major forms of abnormalities is shown in table 2 . The most marked postoperative (I FU) difference between the groups was the occurrence of bilateral disturbances of continuous type which were present in the majority of the CC cases, but only a quarter of the NC cases had such a distribution. Strictly focal findings were rare in the CC group and were absent in the NC group. Unilateral involvement remained unchanged in the noncomplicated cases, and decreased markedly in the complicated cases. No particular region showed specific liability to disturbances and no differences were seen in recovery. Responses to activation procedures were similar in both of the clinical groups.

Background activity Follow-up of the dominant frequency of the background activity is presented in table 2. The postoperative (I FU) fall in the frequency was statistically significant in the CC group (from $10.1 \pm 1.8 \mathrm{c} / \mathrm{s}$ to $8.7 \pm 2.5 \mathrm{c} / \mathrm{s}$, $\mathrm{p}<0.01$ ), while the NC group showed only a slight change in the value (from $10 \cdot 4 \pm 2 \cdot 0$ to $9 \cdot 7 \pm 2 \cdot 7$ $\mathrm{c} / \mathrm{s})$. The difference between the I FU values of the groups was nearly significant $(p<0.05)$. The recovery was rapid in the NC cases and the PRE-OP state was restored within five months after surgery. By contrast recovery was slow in the $\mathrm{CC}$ cases and the PRE-OP values were not regained during the follow-up period.

Hemisphere differences Table 3 shows the follow-up of the incidence of abnormalities in the hemispheres. The left side was affected more often than the right before operation, but impairment after operation involved both hemispheres equally. No interhemispheric differences were seen in the later course of the NC cases, but in the CC group the left hemisphere recovered more slowly than the right hemisphere. EEG and clinical correlates Table 4 shows the

Table 2 Follow-up of the frequency of the background rhythm and the distribution of EEG abnormality

\begin{tabular}{|c|c|c|c|c|c|c|c|c|c|c|c|c|}
\hline \multirow{3}{*}{$\begin{array}{l}\text { Investigation } \\
\text { time }\end{array}$} & \multicolumn{2}{|c|}{$\begin{array}{l}\text { Frequency of background } \\
\text { activity } c / s \pm S D\end{array}$} & \multicolumn{2}{|c|}{$\begin{array}{l}\text { Number of } \\
\text { abnormal EEGs }\end{array}$} & \multicolumn{8}{|c|}{ Percentage of various types of main abnormal activity in the abnormal EEGs } \\
\hline & \multirow[t]{2}{*}{ NC group } & \multirow[t]{2}{*}{ CC group } & \multirow[b]{2}{*}{$N C$} & \multirow[b]{2}{*}{$C C$} & \multicolumn{2}{|c|}{ Focal } & \multicolumn{2}{|c|}{ Diffuse unilateral } & \multicolumn{2}{|c|}{$\begin{array}{l}\text { Diffuse bilateral } \\
\text { episodic }\end{array}$} & \multicolumn{2}{|c|}{$\begin{array}{l}\text { Diffuse bilateral } \\
\text { continuous }\end{array}$} \\
\hline & & & & & $\overline{N C}$ & $C C$ & $\overline{N C}$ & $C C$ & $\overline{N C}$ & $\overline{C C}$ & $\overline{N C}$ & $\overline{C C}$ \\
\hline $\begin{array}{l}\text { PRE-OP } \\
\text { I FU } \\
\text { II FU } \\
\text { III FU } \\
\text { IV FU } \\
\text { V FU }\end{array}$ & $\begin{array}{r}10 \cdot 4 \pm 2 \cdot 0 \\
9 \cdot 7 \pm 2 \cdot 2 \\
9.9 \pm 1.9 \\
10 \cdot 4 \pm 1 \cdot 9 \\
10 \cdot 2 \pm 1 \cdot 8 \\
10 \cdot 5 \pm 2 \cdot 2\end{array}$ & $\begin{array}{c}10 \cdot 0 \pm 1 \cdot 8^{*} \\
8 \cdot 7 \pm 2 \cdot 5^{*} \\
9 \cdot 5 \pm 1 \cdot 6 \\
9 \cdot 8 \pm 1 \cdot 5 \\
9 \cdot 9 \pm 1 \cdot 4 \\
9 \cdot 6 \pm 1 \cdot 4\end{array}$ & $\begin{array}{r}16 \\
22 \\
15 \\
10 \\
10 \\
7\end{array}$ & $\begin{array}{r}16 \\
27 \\
20 \\
11 \\
9 \\
4\end{array}$ & $\begin{array}{l}6 \cdot 3 \\
4 \cdot 5 \\
0 \\
0 \\
0 \\
0\end{array}$ & $\begin{array}{l}6 \cdot 3 \\
7 \cdot 4 \\
0 \\
9 \cdot 1 \\
0 \\
0\end{array}$ & $\begin{array}{l}37 \cdot 5 \\
31 \cdot 8 \\
33 \cdot 3 \\
30 \cdot 0 \\
40 \cdot 0 \\
42 \cdot 9\end{array}$ & $\begin{array}{r}43 \cdot 7 \\
14 \cdot 8 \\
20 \cdot 0 \\
45 \cdot 4 \\
55 \cdot 6 \\
100 \cdot 0\end{array}$ & $\begin{array}{l}50 \cdot 0 \\
45 \cdot 5 \\
46 \cdot 7 \\
60 \cdot 0 \\
50 \cdot 0 \\
57 \cdot 1\end{array}$ & $\begin{array}{l}25 \cdot 0 \\
18 \cdot 5 \\
45 \cdot 0 \\
18 \cdot 2 \\
33 \cdot 3 \\
0\end{array}$ & $\begin{array}{r}6 \cdot 2 \\
18 \cdot 2 \\
20 \cdot 0 \\
10 \cdot 0 \\
10 \cdot 0 \\
0\end{array}$ & $\begin{array}{c}25 \cdot 0 \\
59 \cdot 3 \\
35 \cdot 0 \\
27 \cdot 3 \\
11 \cdot 1 \\
0\end{array}$ \\
\hline
\end{tabular}


Table 3 Right and left hemisphere EEG findings in the NC and CC patient groups

\begin{tabular}{|c|c|c|c|c|c|c|c|c|c|c|}
\hline \multirow[t]{3}{*}{$\begin{array}{l}\text { Investigation } \\
\text { time }\end{array}$} & \multicolumn{2}{|c|}{$\begin{array}{l}\text { Number of } \\
\text { patients }\end{array}$} & \multicolumn{4}{|c|}{$\begin{array}{l}\text { NC group } \\
\text { (non-complicated } \\
\text { patients) }\end{array}$} & \multicolumn{4}{|c|}{$\begin{array}{l}C C \text { group } \\
\text { (complicated patients) }\end{array}$} \\
\hline & \multirow[t]{2}{*}{$N C$} & \multirow[t]{2}{*}{$C C$} & \multicolumn{2}{|c|}{$\begin{array}{l}\text { Right } \\
\text { hem } \\
\text { abnormal } \\
\text { EEG }\end{array}$} & \multicolumn{2}{|c|}{$\begin{array}{l}\text { Left } \\
\text { hem } \\
\text { abnormal } \\
\text { EEG }\end{array}$} & \multicolumn{2}{|c|}{$\begin{array}{l}\text { Right } \\
\text { hem } \\
\text { abnormal } \\
\text { EEG }\end{array}$} & \multicolumn{2}{|c|}{$\begin{array}{l}\text { Left } \\
\text { hem } \\
\text { abnormal } \\
\text { EEG }\end{array}$} \\
\hline & & & $\bar{N}$ & $\%$ & $N$ & $\%$ & $\bar{N}$ & $\%$ & $N$ & $\%$ \\
\hline PRE-OP & 34 & 31 & 12 & $35 \cdot 3$ & 15 & $44 \cdot 1$ & 11 & $35 \cdot 5$ & 14 & $45 \cdot 2$ \\
\hline I FU & 33 & 28 & 18 & $54 \cdot 5$ & 19 & $57 \cdot 6$ & 23 & $82 \cdot 1$ & 26 & 92.9 \\
\hline III FU & 32 & 26 & 7 & 21.9 & 8 & $25 \cdot 0$ & 4 & $15 \cdot 4$ & 9 & $34 \cdot 6$ \\
\hline V FU & 24 & 20 & 5 & $20 \cdot 8$ & 5 & $20 \cdot 8$ & 1 & $5 \cdot 0$ & 3 & $15 \cdot 0$ \\
\hline
\end{tabular}

Table 4 Incidence of clinical signs of cerebral dysfunction in relation to normal and abnormal EEG

\begin{tabular}{|c|c|c|c|c|c|c|}
\hline \multirow{3}{*}{$\begin{array}{l}\text { Investigation } \\
\text { time }\end{array}$} & \multirow{3}{*}{$\begin{array}{l}\text { EEG } \\
\text { Total } N \\
\text { of cases }\end{array}$} & \multirow{2}{*}{\multicolumn{2}{|c|}{$\begin{array}{l}\text { Normal } \\
\begin{array}{l}\text { Clinical signs } \\
\text { present in }\end{array}\end{array}$}} & \multirow{3}{*}{$\begin{array}{l}E E G \\
\text { Total } N \\
\text { of cases }\end{array}$} & \multirow{2}{*}{\multicolumn{2}{|c|}{$\begin{array}{l}\text { Abnormal } \\
\begin{array}{l}\text { Clinical signs } \\
\text { present in }\end{array}\end{array}$}} \\
\hline & & & & & & \\
\hline & & $N$ & $\%$ & & $N$ & $\%$ \\
\hline PRE-OP & 33 & 0 & 0 & 32 & 4 & $12 \cdot 5$ \\
\hline I FU & 12 & 1 & $8 \cdot 3$ & 49 & 27 & $55 \cdot 1$ \\
\hline II FU & 24 & 3 & $12 \cdot 5$ & 35 & 19 & $54 \cdot 3$ \\
\hline III FU & 37 & 5 & $13 \cdot 3$ & 21 & 7 & $33 \cdot 3$ \\
\hline IV FU & 38 & 1 & $2 \cdot 6$ & 19 & 6 & $31 \cdot 6$ \\
\hline V FU & 33 & 1 & $3 \cdot 0$ & 11 & 4 & $36 \cdot 4$ \\
\hline
\end{tabular}

relationship between the EEG and the clinical signs. In general, abnormality of the EEG corresponded with the clinical evaluation particularly when the EEG had been classified as either normal or markedly disturbed. Slight EEG abnormalities, however, reflected the clinical state less reliably. In the whole sample of EEG and neurological investigations (numbering 344), clinical signs were present in $6 \%, 31 \%$ and $70 \%$ of the cases exhibiting a normal EEG, a slightly abnormal EEG and a moderately-severely abnormal EEG respectively.

Figure 3 presents the follow-up of the incidence of normal and abnormal EEG in relation to the presence or absence of clinical signs of CNS involvement. Before operation all four patients displaying cerebral signs also had EEG disturbances. At the first follow-up 10 days after operation) 27 of the 49 cases (55\%) with abnormal EEGs had neurological disorders, but only one of the 12 cases $(8 \%)$ showing a normal EEG displayed clinical signs (those of a brain stem lesion).

Analysis of the cases who exhibited hemiparesis after operation revealed interesting results. Those displaying left-sided signs $(\mathrm{N}=15)$ showed more marked EEG abnormality than the cases with right-sided signs $(\mathrm{N}=4)$. All except of one those with left-sided signs showed bilateral EEG

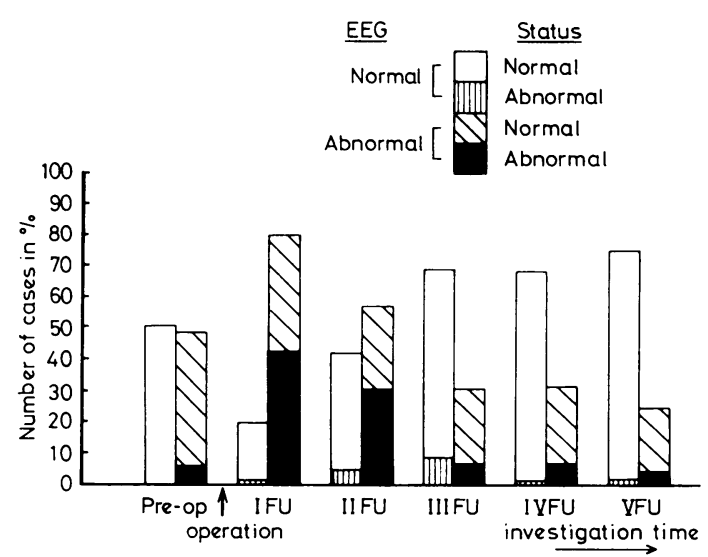

Fig 3 Relationship between EEG and clinical signs of cerebral involvement through the follow-up period.

deterioration, which was seen in only two patients with right-sided signs: in the remaining cases the EEG and clinical findings were compatible in both groups. Comparison of the hemispheres in later months gave remarkable results. In all those with a left-sided hemiparesis, the right hemisphere displayed a normal EEG eight months after operation; the left hemisphere recovered more slowly and still showed abnormalities in one-quarter of the cases up to the end of the study.

Prognostic value of the EEG Some findings before operation were found to have prognostic value: (1) transient delta episodes were seen in eight PRE-OP EEGs; six of these cases displayed neurological signs at the first follow-up examination; (2) five cases out of seven having sharp waves in their PRE-OP EEGs showed signs of hemispheral affection on the same side after operation; (3) when a low $(\leqslant 8.5 \mathrm{c} / \mathrm{s})$ frequency of background activity was observed before operation, the incidence of clinical disorders after operation was $70 \%$ (seven cases out of 10). Using one or more of the above criteria the postoperative clinical outcome could be predicted in 15 cases out of $19(79 \%)$.

The first EEG after surgery had some value in predicting the long-term clinical outcome. All five patients who displayed residual clinical signs one year after operation, as well as one further patient who developed epilepsy a few months after operation, had moderate or severe disturbances in the EEG at the first follow-up examination. Thus six out of the 15 cases showing marked EEG impairment after operation had some kind of long-term neurological disturbance. 


\section{Discussion}

Open-heart operations are high-risk procedures and any measure before operation that might indicate a particularly strong liability to brain damage might be of value in selecting patients. Predictive information would be of special importance to those working without the aid of EEG monitoring during surgery which is useful as a warning of impending disaster. ${ }^{14} 11^{16} 1^{i}$ Unfortunately, clinical and EEG assessments prior to operation generally have failed to predict the after surgery course ${ }^{1322}$ although some prognostic information seems to be provided from neuropsychological studies. ${ }^{23} 24$

In the present investigation, non-complicated and complicated patient groups displayed some EEG differences before operation which were found to have prognostic importance. Preoperative occurrence of bilateral and continuous abnormalities, low frequency of dominant activity, delta range disturbances and sharp wave abnormalities seemed to be associated with clinical complications after operation. By using these preoperative EEG criteria cerebral complications could be predicted in $70 \%$ of the cases displaying these phenomena, but in only $22 \%$ of the whole sample. The present results lead us to conclude, like Lorenz and Hehrlein ${ }^{25}$ that the EEG before surgery mainly indicates the severity of the heart disease producing inadequate cerebral blood flow. However, the fact that it was possible to find at least some criteria with prognostic significance shows that certain EEG disturbances and susceptibility to clinical disorders are inter-related. All the patients in this sample either had normal or only slightly abnormal EEGs before operation and a more reliable predictive measure might be related to disturbed cerebral circulation and metabolism.

EEG surveillance during operations was not included in the present study but 17 of these patients underwent intraoperative quantitative EEG monitoring. ${ }^{26}$ Five of these patients displayed postoperative clinical signs which were predicted in four cases from the monitored EEG, in agreement with previous reports of the predictive value of EEG information during surgery..$^{12} 1416$

The first EEG after operation was 10 days after surgery, by which time slight disturbances may have disappeared. The main aim of this study was to investigate long-term EEG and clinical outcomes and their correlations, so the first postoperative recording was at a time when the patients were able to carry out normal daily activities, when even slight clinical disorders would be recognisable. Also it has been reported that EEG abnormalities are not necessarily at their greatest during the very early postoperative period, but may become more pronounced several days later. ${ }^{27}$

Neurological symptoms after operation are frequent. Although a frequency below $10 \%$ has been reported, ${ }^{28}$ the present incidence $(48 \%)$ is to other earlier results suggesting an incidence between $30 \%$ and $53 \% .^{1-3}$ The strictness of the clinical criteria seems to be one of the major variables in the incidence reported. ${ }^{9} 12$

The EEG findings after operation agreed well with clinical signs when marked EEG deterioration occurred, as has been reported earlier. ${ }^{8}$ Good correspondence also was observed when the first EEG after operation showed no change and particularly when the EEG remained normal. The most significant EEG variables related to clinical signs were the occurrence of delta wave abnormalities, appearance of bilateral continuous disturbances and slowing of the background rhythm. The findings support earlier observations, ${ }^{8}{ }^{25}$ but also emphasise the importance of the changes in the background rhythm.

In contrast the clinical groups showed no differences in the appearance of focal disturbances, in the deterioration rates of the hemispheres and in responses to activation procedures. The present results, with the abundance of clinical signs of focal damage without corresponding focal EEG abnormalities, but with general and bilateral EEG disturbances, show that the operative conditions influence the brain as a whole. In view of the nature of the EEG changes, not all of the clinical signs can be explained by gross embolisation or any similar regionally limited factors. The results support the concept of postoperative cerebral dysfunction resulting from disturbances in cerebral metabolism. ${ }^{56}$ 29 Metabolic disturbances, in turn, may be generated by a number of factors, such as cerebral hypoperfusion, hypoxia, hypothermia, microembolisation of air or antifoam particles and pharmacological effects, all of which are potentially present during extracorporeal circulation.

Interestingly, the hemispheres seemed to have defferences in clinical manifestations. Analysis of the cases displaying postoperative hemiparetic symptoms revealed that the EEG deterioration was most commonly bilateral and affected both hemispheres equally. However, in the majority of the cases the clinical signs were generated by the right hemisphere. There was no obvious explanation for this interhemispheric disparity, 
but in all these cases the right hemisphere was the dominant one. It might be suggested that since the hemispheres differ from each other in several properties such as in neuropsychological ${ }^{30}$ and neurophysiological ${ }^{3132}$ functions, there may also be differences between the dominant and nondominant hemispheres in tolerance to exceptional strains. Also the thresholds in generating clinical manifestations may be different.

The possible special characteristics of the hemispheres, for instance in responding to unusual conditions such as prolonged extracorporeal circulation, have not been investigated.

A considerable ability to recovery, even after longlasting impairment up to 10 days after surgery, seems to be strikingly characteristic of the EEGs of cardiac valvular surgery patients; this confirms previous findings. ${ }^{33}$ Encouragingly, the potential disadvantages of both cardiac valve disease and surgery, that is the negative consequences of prolonged circulatory inadequacy and even occasional operative cerebral damage, seem to be outweighed by the overall benefits and longterm outcome.

This study was supported in part by a grant from Finnish Foundation for Cardiovascular Research.

\section{References}

1 Gilman S. Cerebral disorders after open-heart operations. N Engl J Med 1965; 272:489-98.

2 Javid $H$, Tufo HM, Najafi $H$, Dye WS, Hunter JA, Julian OC. Neurologic abnormalities following open-heart surgery. J Thorac Cardiovasc Surg 1969; 58:502-9.

3 Tufo HM, Ostfeld AM, Shekelle R. Central nervous system dysfunction following open-heart surgery. JAMA 1979; 212:1333-40.

4 Wright G, Sanderson JM. Brain damage and mortality in dogs following pulsatile and nonpulsatile blood flow in extra-corporeal circulation. Thorax 1971; 27:738-47.

5 Branthwaite MA. Cerebral blood flow and metabolism during open-heart surgery. Thorax 1974; 29:633-8.

6 Brennan RW, Patterson RH, Kessler J. Cerebral blood flow and metabolism during cardiopulmonary bypass. Neurology 1971; 21:655-72.

7 Aguilar MJ, Gerbode F, Hill J. Neuropathologic complications of cardiac surgery. $J$ Thorac Cardiovasc Surg 1971; 61:676-85.

8 Witoszka MM, Tamura H, Indeglia R, Hopkins RW, Simeone FA. Electroencephalographic changes and cerebral complications in open-heart surgery. J Thorac Cardiovasc Surg 1973; 66: 855-64.

9 Mohr JP. Neurological complications of cardiac valvular disease and cardiac surgery including systemic hyptotension. In: Vinken PJ, Bruyn GW, eds. Handbook of Clinical Neurology, vol 38. Amsterdam: Elsevier, 1979: Part I, 143-67.

10 Ross Russell RW, Bharucha N. The recognition and prevention of border zone cerebral ischaemia during cardiac surgery. $Q J$ Med 1978; 47:303-23.

11 Jaedicke-Hollender K, Jaedicke W, Steinkrauss G, Barmeyer J, Spillner G. Psychiatrischneurologische Befunde vor und nach aortocoronarer Bypass-Operationen. Nervenarzt 1979; 50:92-101.

12 Sotaniemi KA. Brain damage and neurological outcome after open-heart surgery. $J$ Neurol Neurosurg Psychiatry 1980; 43:127-35.

13 Hansotia PL, Myers WO, Ray JF, Greehling C. Sautter RD. Prognostic value of electroencephalogram in cardiac surgery. Ann Thorac Surg 1975; 19:127-34.

14 Salerno TA, Lince DP, White DN, Lynn RB, Charette EJP. Monitoring of electroencephalogram during open-heart surgery. J Thorac Cardiovasc Surg 1978; 54:557-63.

15 Schwartz MS, Colvin MP, Prior PF et al. The cerebral function monitor. Anaesthesia 1973; 28: 611-8.

16 Kritikou PE, Branthwaite MA. Significance of changes in cerebral electrical activity at the onset of cardiopulmonary bypass. Thorax 1977; 32:534-8.

17 Sulg I, Hokkanen E, Saarela E et al. Computerised quantitative EEG and blood pressure monitoring during high risk surgery. 11th World Congress of Neurology. Amsterdam: Excerpta Medica, International Congress Series No. 427, 1977. Abstract No. 522, 175-6.

18 Jasper HH. The ten twenty system of the international federation. Electroencephalogr Clin Neurophysiol 1958; 10:370-5.

19 Gibbs FA, Gibbs EL. Atlas of electroencephalography III. Reading, Massachusetts: AddisonWesley, 1958.

20 Gibbs FA, Gibbs EL. Atlas of electroencephalography II. Reading, Massachusetts: AddisonWesley, 1959.

21 Gibbs FA, Gibbs EL. Atlas of electroencephalography III. Reading, Massachusetts: AddisonWesley, 1964.

22 Torres F, Frank GS, Gohen MM, Lillehei CW, Kaspar N. Neurologic and electroencephalographic studies in open-heart surgery. Neurology 1959; 9:174-83.

23 Kilpatrick DG, Miller WC, Allan AN, Lee WH. The use of psychological test data to predict open-heart surgery outcome: a prospective study. Psychosom Med 1975; 37:62-73.

24 Willner AE, Rabiner CJ, Wisoff BG et al. Analogy tests and psychopathology at follow-up after open-heart surgery. Biol Psychiat 1976; 11: 678-96.

25 Lorenz R, Hehrlein F. Electroencephalographic findings in heart surgery. Minn Med 1970; 53: 1069-76. 
26 Saarela E, Sulg J, Arranto J, Hokkanen E, Sotaniemi K, Hollmén A. Computerised quantitative EEG and blood pressure monitoring during open-heart surgery. Fifth Congress of Anaesthesiology, Paris 1978. Excerpta Medica, International Congress Series 452, Abstract No. 411.

27 Sachdev NS, Carter CC, Swank RL, Blachly Ph. Relationship between post-cardiotomy delirium, clinical neurological changes, and EEG abnormalities. J Thorac Cardiovasc Surg 1967; 54: 557-63.

28 Branthwaite MA. Prevention of neurological damage during open-heart surgery. Thorax 1975; 30:258-61.

29 Vise WM, Schuier F, Hossman K-A, Takagi S, Zülch KJ. Cerebral microembolisation. Arch Neurol 1977; 34:660-5.
30 Milner B. Interhemispheric differences and psychological processes. Br Med Bull 1971; 27:272-7.

31 Hoovey ZB, Heinemann U, Creutzfeldt OD. Inter-hemispheric "synchrony" of alpha waves. Electroencephalogr Clin Neurophysiol 1972; 32: 337-47.

32 Pfurtscheller $\mathbf{G}$, Maresch $\mathbf{H}$, Schuy S. Inter- and intrahemispheric differences in the peak frequency of rhythmic activity within the alpha band. Electroencephalogr Clin Neurophysiol 1977; 42:77-83.

33 Arfel G, Weiss J, DuBouchet N. EEG findings during open heart surgery with extra-corporeal circulation. In: Gastaut H, Meyer JS, eds. Cerebral Anoxia and the Electroencephalogram. Springfield: Charles C Thomas, 1961: 231-49. 